\title{
Financial and Economic Criteria for Evaluating the Performance of Pharmacies
}

\author{
Ali Imani ${ }^{1}$, Mona Moghimi ${ }^{1}{ }^{2 *}$, Ali Janati ${ }^{1}$, Mina Golestani $^{3}$ and Habib Jalilian ${ }^{2}$ \\ ${ }^{1}$ Health Services Management Research Center, Iranian Center of Excellence in Health Management, School of \\ Management and Medical Informatics, Tabriz University of Medical Sciences, Iran; moghimi.mona@yahoo.com \\ ${ }^{2}$ School of Management and Medical Informatics, Student Research Committee, \\ Tabriz University of Medical Sciences, Iran \\ ${ }^{3}$ Road Traffic Injury Research Center, Tabriz University of Medical Sciences, Iran
}

\begin{abstract}
Improving the economic performance of pharmacies need to economic and financial indicators. Despite this necessity, economic and financial performance indicators have not been identified comprehensively in the pharmacy setting. Thus the aim of this study is to determine the economic and financial performance assessment criteria of the pharmacies by specialist's point of view. This study is a qualitative study in which experts and professional's point of view were gathered by focus group discussion. 15 health system experts were selected by purposive sampling approach. Data from focus group discussions (FGD) were analyzed by thematic analysis method. Twelve main themes in two scopes were obtained to assess the economic and financial performance of the pharmacy by review of specialists view. These themes are waste rate, profitability, cost control, financial management, economic and political issues, pharmacist, doctor, medical insurance, management system, pharmaceutical companies, cultural issues and public or private administration system of pharmacy. Based on the results of this study, the most important criteria to evaluate the financial and economic performance of pharmacies were identified. These results can be used for to economic and financial performance evaluation of pharmacies.
\end{abstract}

Keywords: Economic, Financial, Iran, Performance, Pharmacy

\section{Introduction}

In recent decades, the growth of technology, knowledge and peoples' expectation has lead to inflation of health costs and has created financial problems in health services ${ }^{1}$. Because of limitation of health resources and the importance of providing affordable services, one of the important tasks of health system decision-makers in each country to evaluate the economic performance of health service centers ${ }^{2}$. Unlike the traditional concept of pharmacy (a place for the preparation and delivery of drugs), today, the pharmacy is a growing industry. In recent years the costs of medicines in primary and hospital care have increased and account for $15 \%$ of annual health cost in developed countries ${ }^{3}$.

Economic performance assessment is a key element of health system and this issue is more important in drugs and medicines. Economic assessments of pharmacy are related to pharmacy inputs and outputs, efficient use of resources and provide the evidence for correct decision making. In 1979, the Cost-Benefit Analysis (CBA) of pharmacy services was reported for the first time. At that time, the authors knew, evaluating the benefits and costs of pharmacy services was the only way to increase medical professional services ${ }^{4}$. Economic evaluation models in the United States are similar to CBA studies and represents 45.6 billion dollars cost savings and 120,000 lifesavings. However, despite these figures, the economic evaluation system is not well designed and leads to misconceptions about the health economic performance of Europe. But fortunately, it has been a good starting point to embrace economic evaluation by pharmacies. This study was

* Author for correspondence 
conducted to assess the criteria for performance of pharmacies economically and financially.

\section{Materials and Methods}

This study is a Qualitative research and the focus group discussions were used to gather the views of experts. Participants in this research were pharmacists, faculty of financial, budget management and Medical Sciences, who had an average of 17 years of executive experience. In this study, the purposive sampling approach was used. Sampling and data collection continues until data saturation. In this study, a total of 15 experts were interviewed in 2 group discussions. Discussion group was coordinated, planned and conducted in a proper condition and each session lasted from 90 to 120 minutes.

All FGDs were recorded by the digital sound recording device and transcribed verbatim, then analyzed by thematic analysis. All recorded files were carefully listened to several times and their texts reviewed over and over. All texts were read several times and by breaking any text portion, quotes as significant parts of the themes were extracted. For rigor, consistency and integrity of data, after the end of each part of the group discussion, topics were concluded, participant agreements about the data were asked and accuracy confirmation was received from their perspective. Two faculty members who are experienced in qualitative studies analyzed the contents of the implemented meetings and later the final agreement was incorporated. In this study, ethical considerations, such as oral consent of participants, confidentiality of information and names of people and the right to withdraw from the study at any time were considered.

\section{Results}

In this study, a total of 12 main themes and 101 sub-themes were identified in two scopes including the necessity of evaluating the financial and economic performance of pharmacy and factors affecting the financial and economic performance of pharmacies that are presented in Table 1 and Table 2. Each of the main themes were described separately.

Table 1. The importance of economic and financial performance evaluation of pharmacy from the health professionals and experts' perspective

\begin{tabular}{|c|c|}
\hline Main theme & Sub-theme \\
\hline 1. Waste reduction & $\begin{array}{l}\text { - Storage and depot drugs } \\
\text { - Non-expired drugs based on Stoke quarter } \\
\text { - Pharmacy inventory control } \\
\text { - Unpredictable number of clients } \\
\end{array}$ \\
\hline 2. Profitability & $\begin{array}{l}\text { - Difference in profit margins of selling drugs } \\
\text { - Determination of net and gross profit of drugs } \\
\text { - Determination of expected profit of pharmacy } \\
\text { - Purchase of drugs Award } \\
\text { - Lack of measuring profitability as a routine } \\
\text { - Profit margins of drug } \\
\text { - The impact of medical tourism } \\
\text { - Sale of OTC drugs }\end{array}$ \\
\hline 3. Cost control & $\begin{array}{l}\text { - Rental costs at the pharmacy } \\
\text { - Fixed and current prices } \\
\text { - Personnel costs } \\
\text { - Depreciation costs } \\
\text { - Warehouse handling costs } \\
\text { - Energy costs }\end{array}$ \\
\hline
\end{tabular}




\begin{tabular}{|c|c|}
\hline 4. Financial management & $\begin{array}{l}\text { - Raw data but lack of financial reporting } \\
\text { - Capabilities and problems of HIS system for reporting } \\
\text { - Monitoring the financial balance sheet } \\
\text { - Pharmacy accounting } \\
\text { - Pharmacy debt to pharmaceutical companies } \\
\text { - Delayed registration buying process in HIS system } \\
\text { - Defects in financial software to display Income Profile } \\
\text { - The minimum and maximum inventory in stock } \\
\text { - Circulation of capital } \\
\text { - The collection period } \\
\text { - The beginning and end of year inventory } \\
\text { - The lack of data in the financial system } \\
\text { - Lack of awareness about the need and importance of recording financial information } \\
\text { - Correct and timely registration of financial information } \\
\text { - Pharmacy input and output recording in the financial system } \\
\text { - Analysis of financial data } \\
\text { - Distribution and publication of financial information to all parts of the hospital }\end{array}$ \\
\hline $\begin{array}{l}\text { 5. Political and economic } \\
\text { issues }\end{array}$ & $\begin{array}{l}\text { - Inflation } \\
\text { - Sanctions } \\
\text { - Free market for pharmaceutical companies } \\
\text { - Dynamic economy } \\
\text { - Unpredictable health system } \\
\text { - Taxation and Finance } \\
\text { - The government sanctions } \\
\text { - The government's fiscal policy } \\
\text { - Drug distribution system in the country } \\
\text { - High rates of bank profit }\end{array}$ \\
\hline
\end{tabular}

Table 2. Factors affecting financial and economic performance of pharmacy from the perspective of health professionals and experts

\begin{tabular}{|c|c|}
\hline The main themes & Sub-themes \\
\hline 1. Pharmacist & $\begin{array}{l}\text { - How to buy drugs (buy volume, logical and strategic) } \\
\text { - Determination of the amount of the purchase of pharmaceutical companies } \\
\text { - Buy required items } \\
\text { - Pharmacy processes management } \\
\text { - Pharmacy personnel management } \\
\text { - Patient management for the delivery of appropriate medicines } \\
\text { - Pharmacist's relationship with groups and various sectors } \\
\text { - Management and accounting knowledge of a pharmacist } \\
\text { - Technical Director's authority related to hospital departments } \\
\text { - Presence of a large number of clinical pharmacists in good hospitals } \\
\text { - Pharmacist's technical right } \\
\text { - Monitoring of drug interactions }\end{array}$ \\
\hline 2. Physician & $\begin{array}{l}\text { - Brands used by doctors } \\
\text { - The unique physicians in hospitals } \\
\text { - There is a doctor's office in the pharmacy } \\
\text { - Prescribing systems used by physicians } \\
\text { - Corrosion created in prescriptions by doctors } \\
\text { - Lack of instructions for the physician to use the drug sector }\end{array}$ \\
\hline
\end{tabular}




\begin{tabular}{|c|c|}
\hline 3. Medical insurance & $\begin{array}{l}\text { - Health insurance deductions } \\
\text { - Late or untimely payment of health insurance } \\
\text { - Unilateral insurance system } \\
\text { - Insurance system differences in comparision with other countries } \\
\text { - High deductions compared with other countries } \\
\text { - Absence of a fixed system in Insurance } \\
\text { - Costs imposed on the insurance by providing software and CD-ROM } \\
\text { - Hidden deductions }\end{array}$ \\
\hline 4. Management system & $\begin{array}{l}\text { - Keep the Hospital committees for Drug, Therapeutic and Deductions active, } \\
\text { therapeutic and deductions committees of hospital } \\
\text { - The prorated deductions to all departments of the hospital } \\
\text { - Pharmacy incomes spent in other parts of the hospital } \\
\text { - Distribution and delivery process of medicines in the hospital } \\
\text { - Financial resource management } \\
\text { - The new financial system } \\
\text { - Role of Pharmacists Association } \\
\text { - Role of Food and Drug Department } \\
\text { - Seasonal scarcity of medicines } \\
\text { - Therapeutic interest in Health Ministry } \\
\text { - Supervision of university authorities to prevent issues of corruption and fraud } \\
\text { management } \\
\text { - Financial knowledge of managers } \\
\text { - Delays in the reimbursement to pharmaceutical companies }\end{array}$ \\
\hline $\begin{array}{l}\text { 5. Pharmaceutical compa- } \\
\text { nies }\end{array}$ & $\begin{array}{l}\text { - Mafia in the chain of companies } \\
\text { - Different importers of medications } \\
\text { - Different prices for different companies } \\
\text { - Reject expired drugs from pharmaceutical companies } \\
\text { - Investment pharmacies for all brands of pharmaceuticals } \\
\text { - Promotion and marketing of pharmaceutical companies }\end{array}$ \\
\hline 6. Cultural issues & $\begin{array}{l}\text { - Community opinion about the pharmacy } \\
\text { - Clients culture of pharmacy } \\
\text { - Culture of the pharmaceutical society } \\
\text { - Conflict between public culture and academic cycle } \\
\text { - Traditional and personalised pharmacy management system } \\
\text { - Customer focus and respect to customer }\end{array}$ \\
\hline $\begin{array}{l}\text { 7. Public or private } \\
\text { management system of } \\
\text { pharmacy }\end{array}$ & $\begin{array}{l}\text { - The number of personnel in the public and private sectors } \\
\text { - Costs and cost control in the public and private sectors } \\
\text { - Public and private sector, goals } \\
\text { - Sale of subsidized and essential drugs in the public sector } \\
\text { - Rents in the public sector }\end{array}$ \\
\hline
\end{tabular}

\subsection{Waste Reduction}

Due to the limitation of financial resource waste reduction is one of the essential solutions for resource conservation. Knowledge about Drug Purchase, Inventory control and method of disposing the expired drugs were emphasized by the participants. "We try not to purchase expired medication because our shopping is based on three months' supply" (P.9). "We all know that financial turnover should be right e.g. do not shop something that stays for a a long time in stock and leads to negative turnover"(P.1).

\subsection{Profitability}

One of the most important issues that participants emphasized in the discussion group was the question of profitability of their pharmacy. In this regard issues such as the difference in the profitability of pharmacies, drug 
profit margins, impact of medical tourism, purchase of medication award, sale of non-prescription drugs (OTC) and expected profit of pharmacies are very important and need to be considered. "In relation to the financial and economic evaluation of the pharmacy or hospital, the first argument is that in addition to providing technically appropriate and acceptable services, it must be profitable and the pharmacy must show a $20 \%$ profit. (P.8). "Iran is the only country where profit is so low for medication sales. Now we have a $70 \%$ or $80 \%$ profit in the European countries. In America the drug profit is $68 \%$ with less investment whereas here it is just the opposite.

\subsection{Costs Control}

All participants agreed on the need to carefully examine and control all expenditures. "If we consider the rest and staff expenditure, a pharmacy must make sales of 3 to 4 million every month to cover these costs." (P.12). "A model calculation should consider the cost of energy and space consumption too". (P.6).

\subsection{Financial Management}

All participants agreed that it was tedious to collect and analyze financial information across pharmacies to establish a relationship between earnings and expenditure. In this regard, the following aspects were important; the type of software used, software users, timely and accurate recording of financial information, lack of data in the system, distribution and dissemination of financial information. "If the available raw data includes the purchase, sales and the costs, we can turn the data into good financial reporting, but there is no final conclusion."(P.6). "We have created the information system in our collection but it is necessary to compel to be timely and accurate" (P.4).

\subsection{Economic and Political Issues}

Issues related to society and nation bear an effect on Pharmacy and health system. Participants emphasized about the sanctions, inflation, fiscal policy, free and dynamic economy as well as the country's drug distribution system. "Pharmacy industry and the pharmacist are the ones who face the problems with respect to Foreign exchange and other sanctions". (P.2). Problems in our asset management is seen when different drugs have different profit percentage margins, but the system calculates all in the same manner of it have a $17 \%$ profit, but in our asset system all these are calculated in the same manner"(P.13).

\subsection{Pharmacist}

Many participants insisted on guidance on purchase strategy and supply, process and personnel management, control and monitoring of drug interactions as well as technical contributions. In the first group discussion it was said: "must be careful in purchases, items that are needed, the brands that will be used and prevention of longtime purchase" (P.8). "No matter how technically correct the pharmacist is, there is no legal right issued by parliament to feel comfortable".(P.13).

\subsection{Physician}

In focus group discussions, most participants agreed upon the role of physicians in pharmacy economy. They believed that doctors can influence by their presence and recommend certain medicines, specific brands and write prescriptions accordingly as well as direct patients to nearby pharmacies. All these will play a major role in Pharmacy economic management. "Problem is interacting with doctors. Problems will exist as long as prescribed medicines are not available and doctors need to be convinced to prescribe as per circulars etc. "Pharmacy is always dependent on the doctor, depending on the doctor's prescription, the medication prescribed by the doctor..."(P.15).

\subsection{Health Insurances}

All participants emphasized on issues about Insurance deductions, Delayed payment or untimely payment by insurance companies, unilateral insurance system and lack of proper system in Insurance section. "This system is completely one-sided. Therefore, as a pharmacist against the health insurance system I do not have any role in decision-making" (P.11). One of the factors that affects the pharmacy economy is the deductions, where there is a loss to the pharmacy profit".(P.8).

\subsection{Management System}

Form an active drug committee which monitors the medicine distribution in the country. Managers should be knowledgeable about the financial ratios. The point of view by the ministry was another important factor mentioned by participants. "A management with poor vision, affects 
the pharmacy and health care management system, which indicates that the perspective of the Ministry of health is therapeutic and not pharmaceutical'. (P.11)."I think a lot of our managers are not familiar with financial ratios and do not know what their applications are..."(P.6).

\subsection{Pharmaceutical Companies}

From the participant's point of view, different drug importers, different prices of pharmaceutical companies, different pharmaceutical companies, and its marketing manners are other factors that affect the economic and financial pharmacy management. "Iran's generic pharmacy plans have changed and now all companies are allowed to have their own brand name. While purchasing at a pharmacy, this is another problem for us to recall the name".(P.14)."Each pharmaceutical company has its own price and this differs across companies. All these make the society skeptical" (P.12).

\subsection{Cultural Issues}

From a participant's perspective, the culture was another factor influencing pharmacy management. Patients referring to pharmacies, socially settled, conflict between traditional and academic culture of pharmacies as well as personalized management were all factors affecting the pharmacy management. "In the drug issue, consumer culture should be considered as a cycle, distribution culture, pharmacy management culture, particular culture of the city and neighborhood special culture" needs to be considered (P.11). "Recently, pharmacy colleges resumed the past continuous cycle for training pharmacists. Each pharmacist, managed pharmacy in his own way..." (P.12).

\subsection{Public or Private Pharmacy Management System}

In participants perspective different management in public and private pharmacies was one of the other factors that impact economic and financial management. Participants mentioned the key factors, including the difference in the number of personnel, costs and objectives, "There is none in the private sector. For example, the commission does not exist in the private sector, if insurance is delayed in private sector, they cancel the contract and do not work with that insurance company, but can the government do it?" (P.4). "The government system requires a huge number of financial and administrative documents along with a huge number of personnel..."(P.1).

\section{Discussion}

The necessity of implementation of economic and financial performance evaluation in a pharmacy was the first scope that was examined by specialists and experts. The findings of FGDs show that all participants confirm the economic and financial evaluation of pharmacy as the necessity of health care system and there was a consensus among all participants in this regard.

Review study at the University of Chicago (2009) was conducted to evaluate pharmacy services, that emphasized on the necessity of evaluation of pharmacy services and outcomes. General proposed model for evaluation of pharmacy services in this study as Bethany's study in the UK, focused on two aspects of costs and outcomes of pharmacy ${ }^{5,6}$. Also in another study in the field of hospital pharmacies in Canada, the necessity of attention to health economic was expressed by the proper use of resources especially in the field of hospital pharmacy ${ }^{7}$. In a study that was conducted to survey the status of pharmacy information systems of Shahid Beheshti University of Medical Sciences affiliated hospitals in 2009, pharmacy information systems were semi-mechanized and the collecting, reporting and processing of information was implemented incompletely ${ }^{8}$. Therefore, proper design and analysis of pharmacy information system, either in financial and functional dimension is one of the necessities of pharmacy management.

The problem in evaluating economic performance of the pharmacy is poor quality of studies in this field. In the review (1987-2005) that was conducted in Zimbabwe, limitation and poor quality of studies in the field of the financial and economic performance evaluation were expressed. Political and economic issues such as inflation, poverty, unemployment and diseases such as AIDS were the most important factors which affect this episode ${ }^{9}$. In another study in America that was conducted at organizational factors affecting the performance of pharmacies, operating pharmacy system, volume of prescriptions and pharmacy staff were used as the core of gathering information ${ }^{10}$.

Factors affecting the financial and economic performance evaluation of pharmacies were one of the another scope that was discussed in the meetings. From the participant specialists point of view, pharmacists, physicians, medical insurance, management system, pharmaceutical companies, cultural issues and public or private pharmacy administrative system were most 
important factors in the evaluation of financial and economic performance. In the cross-sectional study that was conducted in Lebanon and Canada pharmacies, the professional and influencing role of pharmacists and professional behavior of pharmacists were the key factors in pharmacy performance. Also in the field of financial satisfaction, $50 \%$ of the pharmacists who had private pharmacies were satisfied but hospital pharmacies were dissatisfied. This reflects the importance of the pharmacy administrative system.

In a study that was conducted in 2003 in hospitals, attention was paid to key issues related to medical costs. The key role of doctors and their prescribed medication in rising costs were one of these factors ${ }^{11}$. Public or private administrative pharmacy system was one of the very important factors that the expert participants emphasized on its importance on the economic and financial performance evaluation. Some of the participants expressed the need for devolution of hospital pharmacy to private sector and the positive experiences in this field. In Tourani et al. study that was conducted to compare the effectiveness and efficiency of Firoozgar Hospital pharmacy before and after the outsourcing, findings of the study showed that after outsourcing the number of pharmacy prescriptions increased and huge amounts of personal costs and pharmacy expenditure were saved monthly. This represents that outsourcing of Firoozgar Hospital pharmacy was successful ${ }^{12}$.

\section{Conclusion}

Based on the results of this study, necessary criteria and indicators to assess the economic and financial performance of pharmacies as per professional and experts view were identified. Using the results of this study an effective tool to evaluate economic and financial performance of pharmacies can be developed.

\section{References}

1. Murray CJ, Knaul F, Musgrove P, Xu K, Kawabata K. Defining and measuring fairness in financial contribution to the health system. Geneva: World Health Organization; 2001.

2. Torrance GW. Measurement of health state utilities for economic appraisal: a review. Journal of Health Economics. 1986; 5(1):1-30.

3. Tordoff JM, Norris PT, Reith DM. Price management and its impact on hospital pharmaceutical expenditure and the availability of medicines in New Zealand hospitals. Value in Health. 2008; 11(7):1214-26.

4. Schumock GT, Butler MG, Meek PD, Vermeulen LC, Arondekar BV, Bauman JL. Evidence of the economic benefit of clinical pharmacy services: 1996-2000. Pharmacotherapy: The Journal of Human Pharmacology and Drug Therapy. 2003; 23(1):113-32.

5. George B, Silcock J. Economic evaluation of pharmacy services-fact or fiction? Pharmacy World and Science. 1999; 21(4):147-51.

6. Anderson SV, Schumock GT. Evaluation and justification of clinical pharmacy services. Expert Rev Pharmacoecon Outcomes Res. 2009; 9(6):539-45.

7. Payne K, Proskorovsky I. A health economics survey of European hospital pharmacists. European Journal of Hospital Pharmacy Science. 2007; 13(2):33.

8. Asadi F, Moghaddasi H, Hosseini A, Maserrat E. A survey on pharmacy information system at hospitals affiliated to Shahid Beheshti University of Medical Sciences; 2009. Journal of Health Administration. 2009; 13:41.

9. Gavaza P, Rascati K, Brown C, Lawson K, Mann T. The state of health economic and pharmacoeconomic evaluation research in Zimbabwe: a review. Current Therapeutic Research. 2008; 69(3):268-85.

10. Doucette WR, Nevins JC, Gaither C, Kreling DH, Mott DA, Pedersen CA, et al. Organizational factors influencing pharmacy practice change. Research in Social and Administrative Pharmacy. 2012; 8(4):274-84.

11. Franklin GA. The driving force in hospital formularies: economics versus efficacy. The American Journal of Surgery. 2003; 186(5):55-60.

12. Tourani S, Maleki M, Ghodousi-Moghadam S, Gohari M. Efficiency and Effectiveness of the Firoozgar Teaching Hospital's Pharmacy after Outsourcing, Tehran, Iran. Journal of Health Administration. 2010; 12(38):59-70. 